\title{
Effects of CD2-associated protein deficiency on amyloid- $\beta$ in neuroblastoma cells and in an APP transgenic mouse model
}

\author{
Fan Liao ${ }^{1}$, Hong Jiang ${ }^{1}$, Subhashini Srivatsan², Qingli Xiao ${ }^{3}$, Katheryn B Lefton ${ }^{4}$, Kaoru Yamada ${ }^{5}$, Thomas E Mahan ${ }^{4}$,
} Jin-Moo Lee ${ }^{3}$, Andrey S Shaw ${ }^{2}$ and David M Holtzman ${ }^{1 *}$

\begin{abstract}
Background: CD2-associated protein (CD2AP) is an SH3-containing scaffold adaptor protein which regulates the actin cytoskeleton. Recently, CD2AP was identified as a genetic risk factor for Alzheimer's disease (AD) by several genome-wide association studies. One of the hallmarks of $A D$ is the accumulation of aggregated forms of Amyloid- $\beta$ $(A \beta)$ in the brain. In humans, CD2AP AD susceptibility locus (rs9349407) is associated with an increased plaque burden. $A \beta$ production is highly regulated by endocytosis and is influenced by lysosomal function. Lysosomal trafficking is influenced by CD2AP. In this study, we decreased CD2AP levels in N2a neuroblastoma cultures and PS1APP mice and analyzed $A \beta$ levels and plaque burden.
\end{abstract}

Results: Our data show that suppressing CD2AP expression using shRNA in N2a-APP695 cells results in decreased cell membrane amyloid precursor protein, decreased $A \beta$ release and a lower $A \beta_{42} / A \beta_{40}$ ratio. CD2AP protein is expressed in the brain as detected by western blot, and the expression level is dependent on gene dosage. In 1-month old PS1APP mice, complete loss of CD2AP in brain resulted in a decreased $A \beta_{42} / A \beta_{40}$ ratio in brain tissue lysates while there was no effect on A $\beta$ deposition or accumulation in PS1APP mice expressing one copy of CD2AP.

Conclusion: $C D 2$-Associated Protein affects $A \beta$ levels and $A \beta_{42} / A \beta_{40}$ ratio in vitro. The effect of $C D 2$-Associated Protein on $A \beta$ metabolism is subtle in vivo.

Keywords: CD2AP, Alzheimer's disease, Amyloid- $\beta$

\section{Background}

CD2-associated protein (CD2AP) was originally identified as a scaffold protein required for organization of the immunological synapse - the specialized interface between a $\mathrm{T}$ lymphocyte and an antigen-presenting cell [1]. It was later shown that CD2AP, by virtue of its multiple protein-protein binding modules, interacts with multiple proteins involved in diverse biological processes. These associations have implicated CD2AP in receptor tyrosine kinase internalization, actin cytoskeleton remodeling and vesicular trafficking [2].

Alzheimer's disease (AD) is a neurodegenerative disorder characterized by the impairment of memory and other

\footnotetext{
* Correspondence: holtzman@neuro.wustl.edu

'Department of Neurology, Hope Center for Neurological Disorders, Charles F. and Joanne Knight Alzheimer's Disease Research Center, Washington University School of Medicine, St. Louis, MO, USA

Full list of author information is available at the end of the article
}

cognitive functions as well as the presence of extracellular amyloid plaques and intracellular neurofibrillary tangles [3]. There is substantial evidence indicating that amyloid- $\beta$ (A $\beta$ ) plays an essential role in the development of $\mathrm{AD}[4,5]$. The deposition of $A \beta$ into amyloid plaques is dependent on the concentration of brain interstitial fluid $A \beta$ [6], which is regulated by endocytosis [7]. Recently CD2AP was detected as a risk factor for $\mathrm{AD}$ by several genomewide association studies [8-10]. In a yeast model for cellular toxicity elicited by $A \beta$, a functional homolog of CD2AP [11] was identified as a suppressor of $A \beta$ toxicity [12]. In addition, a recent study in humans suggests that CD2AP AD susceptibility locus (rs9349407) is associated with increased plaque burden [13]. However, the relationship between $C D 2 A P$ and $A \beta$ has never been reported in mammalian cells or in mouse models expressing human amyloid precursor protein (APP)/A $\beta$. 
Since the reported AD susceptibility locus (rs9349407) which has impact on plaque load in humans [13] is in the CD2AP gene, we asked whether manipulating CD2AP expression level affects $A \beta$ levels. In the current study, we knocked down CD2AP expression in N2a-APP695 cells and observed a decrease in $A \beta$ levels as well as the ratio of $A \beta_{42} / A \beta_{40}$ in the cell culture medium. We crossed CD2AP knockout mice with PS1APP mice and observed a reduction of $A \beta_{42} / A \beta_{40}$ in the brain tissue. Due to the fact that CD2AP knockout mice have glomerular disease and do not survive beyond a few months of age until plaque onset in PS1APP mice [14], we also measured the effects of CD2AP haploinsufficiency on amyloid plaque deposition. There was no effect of CD2AP haploinsufficiency on $A \beta$ deposition up to 7 months of age.

\section{Results and discussion}

Effects of CD2AP deficiency in cultured N2a-APP695 cells APP processing is regulated by endocytosis. Given that CD2AP plays an important role in regulating endocytosis, we first tested whether CD2AP has an effect on $A \beta$ synthesis or $A \beta$ release in cultured cells. We used CD2AP shRNA to knockdown CD2AP levels (Figures 1, 2A) in neuroblastoma N2a-APP 695 cells and measured $A \beta$ in the cell lysates and $\mathrm{A} \beta$ released into the cell culture medium. The results showed that CD2AP sh RNA1 (Sh1) significantly decreased both $A \beta_{40}$ and $A \beta_{42}$ secreted into the culture medium by about $20 \sim 30 \%$ (Figure 1A,B) while the $A \beta_{40}$ and $A \beta_{42}$ in cell lysates were not affected (Figure 1D,E). CD2AP sh2 had greater effects on the $A \beta_{42}$ in the medium as compared to CD2AP sh1 (Figure $1 \mathrm{~A}, \mathrm{~B}$ ). The $\mathrm{A} \beta_{40}$ and $A \beta_{42}$ in cell lysates were increased about $30 \%$ by CD2AP sh2 (Figure 1D,E). Interestingly, both CD2AP sh1 and CD2AP sh2 decreased the $A \beta_{42} / A \beta_{40}$ ratio in cell culture medium (Figure $1 C$ ). However, the $A \beta_{42} / A \beta_{40}$ ratios in cell lysates were unaltered (Figure 1F). We further examined the total APP and APP on the cell surface in these N2a cells. The results showed that $\mathrm{CD} 2 \mathrm{AP}$ sh1 and sh2 did not change total APP levels in N2a cells (Figure 2B,D). However, membrane APP levels were decreased by CD2AP sh1 and sh2 (Figure 2B,C). In cells, nascent APP is posttranslationally modified and transported from the endoplasmic reticulum to the plasma membrane [15]. To be proteolytically cleaved into A $\beta$, APP must be internalized from the cell surface into the cell and transported to endosomes where $\beta$-secretase and $\gamma$-secretase complexes cleave APP to produce $A \beta[7,16]$. In the current study,

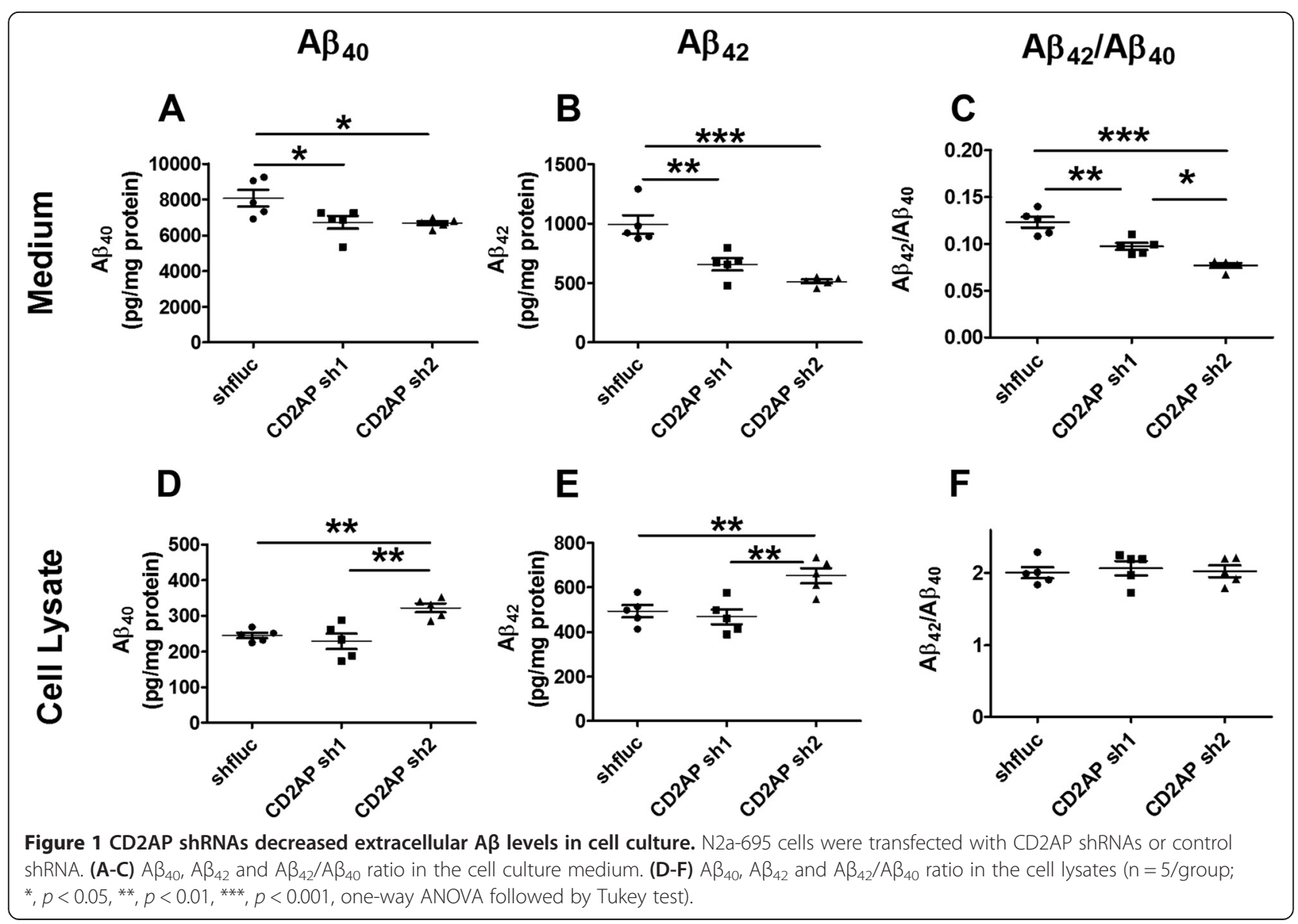




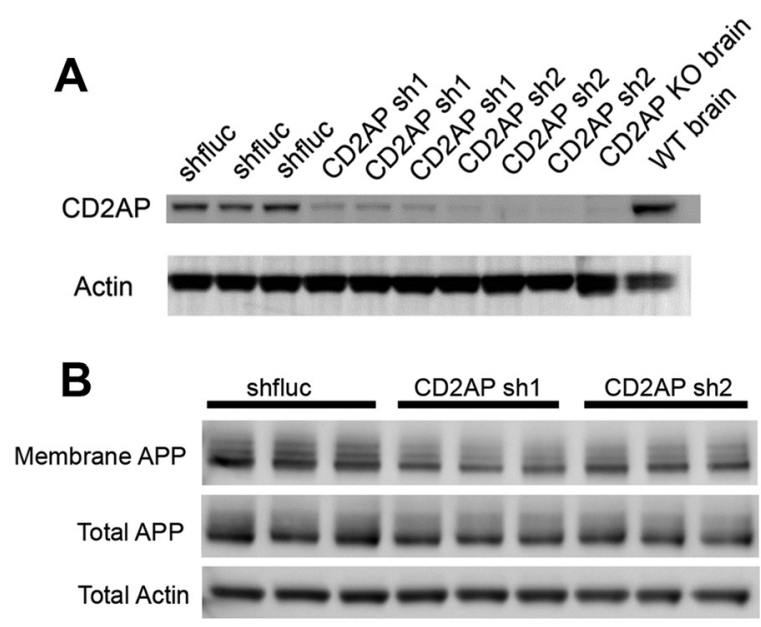

C

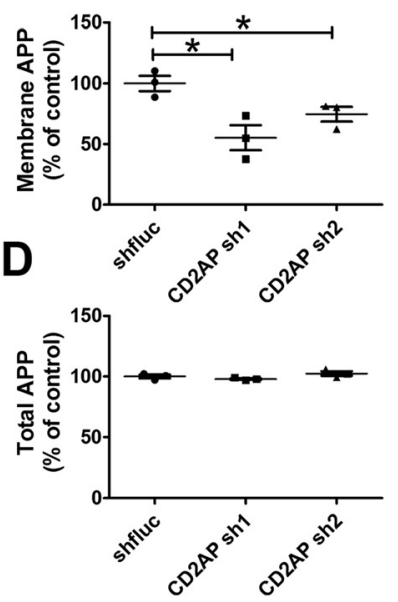

Figure 2 CD2AP shRNAs decreased cell membrane APP. (A) CD2AP and actin levels in cells transfected with CD2AP shRNAs or control shRNA. (B) Membrane and total APP levels in the cells transfected with CD2AP shRNAs or control shRNA. (C-D) Quantification of membrane APP and total APP in $H$ ( $n=3$ /group, ${ }^{*}, p<0.05$, Student's $t$-test).

knocking down CD2AP in N2a-APP695 cells may decrease APP on cell surface which would result in less APP getting into endosomes and less $A \beta$ being released into cell culture medium.

\section{Expression of CD2AP in the brain}

Before we studied the effects of $C D 2 A P$ on $A \beta$ pathology in vivo, we first determined whether CD2AP is expressed in the brain and whether the expression level correlates with CD2AP gene dosage. Using western blot, we detected $\mathrm{CD} 2 \mathrm{AP}$ in $\mathrm{CD} 2 \mathrm{AP}^{+/+}$brains with $\mathrm{CD} 2 \mathrm{AP}^{-/-}$brains serving as a negative control (Figure $3 \mathrm{~A}$ ). As reported in the kidney [17], CD2AP protein level in the brains of mice with CD2AP haploinsufficiency $\left(\mathrm{CD}_{2} \mathrm{AP}^{+/-}\right)$is about $50 \%$ of the level in $\mathrm{CD}_{2} \mathrm{AP}^{+/+}$mice (Figure 3B).

\section{Effects of CD2AP knockout on brain $A \beta$ levels in 1-month old PS1APP mice}

Next, we assessed whether CD2AP has similar effects on $A \beta$ levels and $A \beta_{42} / A \beta_{40}$ ratio in vivo. If CD2AP affects $A \beta$ production or release, we would expect to see the changes in young mice before plaque deposition. Therefore, we generated 1-month old PS1APP/CD2AP ${ }^{+/+}$(female, $\mathrm{n}=6$; male, $\mathrm{n}=6$ ) and PS1APP/CD2AP ${ }^{-/-}$(female, $\mathrm{n}=7$; male, $n=5$ ) mice and measured $A \beta_{40}$ and $A \beta_{42}$ levels in the PBS soluble fraction of cortical tissue. The results showed that there were no significant changes in the absolute concentration of $A \beta_{40}$ and $A \beta_{42}$ (Figure 4A,B). However, the ratio of $A \beta_{42} / A \beta_{40}$ was lower in PS1APP/ $\mathrm{CD} 2 \mathrm{AP}^{-/-}$mice as compared to PS1APP/CD2AP ${ }^{+/+}$ mice (Figure $4 \mathrm{C}$ ). This effect was similar in both females $\left(0.37 \pm 0.008\right.$ vs $0.29 \pm 0.0025$ for PS1APP/CD2AP $\mathrm{A}^{+/+}$vs
PS1APP/CD2AP ${ }^{-/-}$, respectively, $p<0.05$, Student's $t$-test) and males $(0.35 \pm 0.015$ vs $0.30 \pm 0.010$ for PS1APP/ $\mathrm{CD} 2 \mathrm{AP}^{+/+}$vs PS1APP/CD2AP ${ }^{-/-}$, respectively, $p<0.05$, Student's $t$-test).

Although inhibiting CD2AP expression levels in cultured cells resulted in decreased levels of $A \beta$ in the cell culture medium, we did not observe changes in the absolute concentration of cortical $A \beta_{42}$ or $A \beta_{40}$ in CD2AP knockout

A

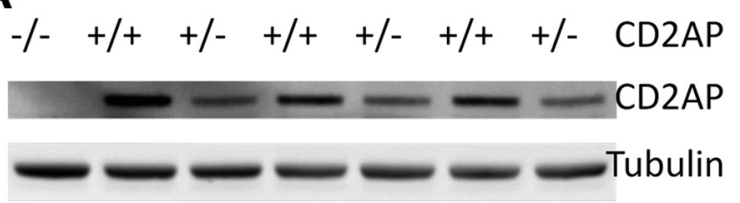

B

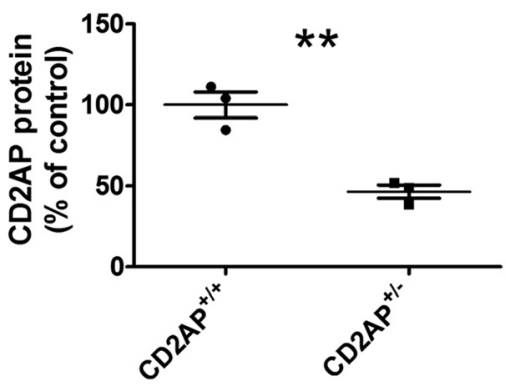

Figure 3 CD2AP protein was expressed in the brain. (A) Western blot for CD2AP and tubulin in cortices from CD2AP ${ }^{-/-}, \mathrm{CD}_{2} \mathrm{AP}^{+/-}$and CD2AP $P^{+/+}$mice. (B) Quantification of CD2AP levels in CD2AP ${ }^{+/-}$and $\mathrm{CD}_{2} \mathrm{AP}^{+/+}$mice in western blot presented in $\mathrm{A}$. $\left(\mathrm{n}=3\right.$ /group, ${ }^{* *}, p<0.01$, Student's $t$-test). 
A

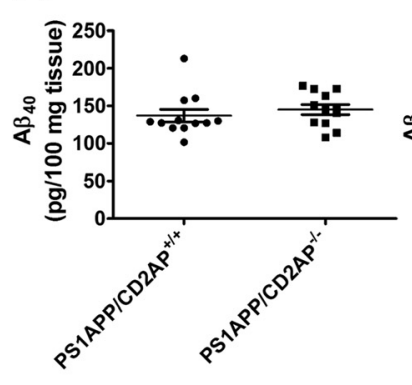

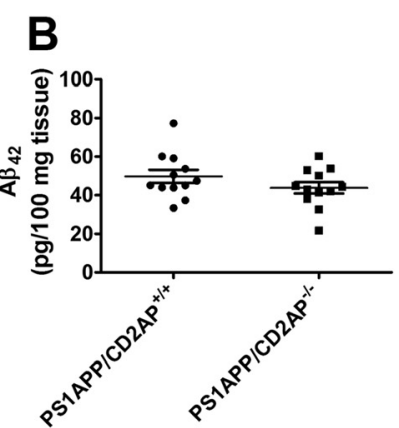

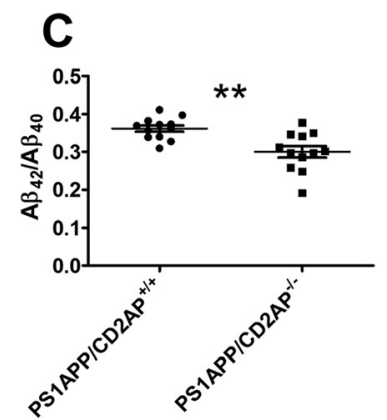

Figure 4 Effects of CD2AP on A $\boldsymbol{\beta}$ levels in 1-month old PS1APP mice. PS1APP/CD2AP ${ }^{+/+}$( $n=12$ total, 6 females and 6 males) and PS1APP/CD2AP ${ }^{-1-}\left(n=12\right.$ total, 7 females and 5 males) mice were sacrificed at 1-month of age. The cortices were homogenized in PBS. $A \beta_{40}(\mathbf{A}), A \beta_{42}$ (B) and $A \beta_{42} / A \beta_{40}(C)$ ratio were measured. (**, $p<0.01$, Student's t-test).

PS1APP mice as compared to PS1APP mice expressing two copies of CD2AP. While A $\beta$ levels in cultured APP-expressing N2a-APP695 cells are mainly determined by APP processing, A $\beta$ levels in vivo are regulated not only by $A \beta$ production and release but also $A \beta$ uptake and degradation by different cell types, $A \beta$ clearance mediated by interstitial fluid (ISF) and cerebrospinal fluid (CSF) bulk flow and $A \beta$ transport across the blood brain barrier. Among these mechanisms, many of them are regulated by vesicular trafficking, which can be influenced by manipulating CD2AP levels. For example, disruption of endocytosis in neurons inhibits APP processing and reduces $A \beta$ levels [7]. On the other hand, disruption of endocytosis in the microglia or astrocytes could result in an increase of extracellular $A \beta$ due to decreased $A \beta$ uptake and degradation [18]. Therefore, these effects could theoretically cancel each other out when knockout of CD2AP occurs in all the cell types. This may explain why we did not observe the same change in A $\beta$ concentration in vivo as we have seen in vitro.

In cultured N2a-APP695 cells, knocking down CD2AP resulted in a lower $A \beta_{42} / A \beta_{40}$ ratio. Similar changes also occurred in the soluble $A \beta_{42} / A \beta_{40}$ ratio in 1-month old $\mathrm{PS} 1 \mathrm{APP} / \mathrm{CD} 2 \mathrm{AP}^{-/-}$mice as compared to PS1APP/ $\mathrm{CD} 2 \mathrm{AP}^{+/+}$mice. The ratio of $\mathrm{A} \beta_{42} / \mathrm{A} \beta_{40}$ is determined by $\gamma$-secretase cleavage of APP. Mutations of presenilin, an active enzymatic component of the $\gamma$-secretase complex, lead to autosomal dominant familial $\operatorname{AD}[19,20]$ likely in large part due to an increased $A \beta_{42} / A \beta_{40}$ ratio. On the other hand, mutations in APP [21] or gamma secretase modulators [22] can influence $\gamma$-secretase cleavage and alter the $A \beta_{42} / A \beta_{40}$ ratio. Some molecules such as phosphatidylinositol clathrin assembly lymphoid-myeloid leukemia (PICALM) shift the $A \beta_{42} / A \beta_{40}$ ratio through affecting internalization of $\gamma$-secretase [23]. In the current study, the change of $A \beta_{42} / A \beta_{40}$ ratio occurred before plaque deposition, suggesting CD2AP knockout could affect the selective production of $A \beta_{40}$ and $A \beta_{42}$. Since CD2AP binds membrane proteins, it could affect $A \beta$ cleavage by interacting with $\gamma$-secretase complex, by modifying APP directly or through some intermediary molecules to shift the ratio of $A \beta_{42} / A \beta_{40}$. It is shown recently that a homolog of Nephrin, a protein interacting with CD2AP [14], is required for $\gamma$-secretase mediated Notch and APP-like cleavages in Drosophila [24].

\section{Effects of CD2AP haploinsufficiency on amyloid deposition in 7-month old PS1APP mice}

Shifting the ratio of $A \beta_{42} / A \beta_{40}$ results in an altered time course of plaque deposition in both humans $[19,20]$ and mice [25]. Since we observed changes in the $A \beta_{42} / A \beta_{40}$ ratio in cultured cells and 1-month old PS1APP mice, we next asked whether CD2AP deficiency affects amyloid plaque load in older PS1APP mice. CD2AP ${ }^{-/-}$mice have $\mathrm{a} \sim 6$-week life-span due to renal failure [14] while the average plaque onset age in PS1APP mice is at $\sim 4$-month. Therefore, we were not able to assess plaque deposition in PS1APP/CD2AP ${ }^{-/-}$mice. Mice with CD2AP haploinsufficiency (CD2 $\mathrm{AP}^{+/-}$) live a normal life span but express $\sim 50 \%$ less CD2AP in the brain compared to $\mathrm{CD}_{2} \mathrm{AP}^{+/+}$mice (Figure $3 \mathrm{~A}, \mathrm{~B}$ ). We therefore asked whether a $\sim 50 \%$ reduction of CD2AP levels affects $\mathrm{A} \beta$ pathology in PS1APP mice. We generated PS1APP/ $\mathrm{CD} 2 \mathrm{AP}^{+/-}$and PS1APP/CD2AP $\mathrm{AP}^{+/+}$mice and characterized their $A \beta$ pathology at the age of 7 -months. We first measured $A \beta$ levels in the cortical tissue lysates. The results showed no difference in the absolute level of $A \beta_{40}$ and $A \beta_{42}$ in the PBS (soluble forms of $A \beta$ ), Triton or Guanidine (insoluble forms of $A \beta$ ) brain fractions between PS1APP/CD2AP ${ }^{+/-}$and PS1APP/CD2AP $\mathrm{AP}^{+/+}$ groups (Figure 5). In the $\mathrm{PBS}$ soluble fraction, the $\mathrm{A} \beta_{42} / \mathrm{A} \beta_{40}$ ratio in the female PS1APP/CD2AP $\mathrm{AP}^{+/-}$group was significantly lower than that in female PS1APP/ $\mathrm{CD}_{2} \mathrm{AP}^{+/+}$group $(p<0.05$, Student's $t$-test). However, the effects on males tended to trend in the opposite direction (Figure 5). In the Triton and Guanidine fractions, there was no change in the $A \beta_{42} / A \beta_{40}$ ratio associated with $\mathrm{CD} 2 \mathrm{AP}$ gene status (Figure 5). 


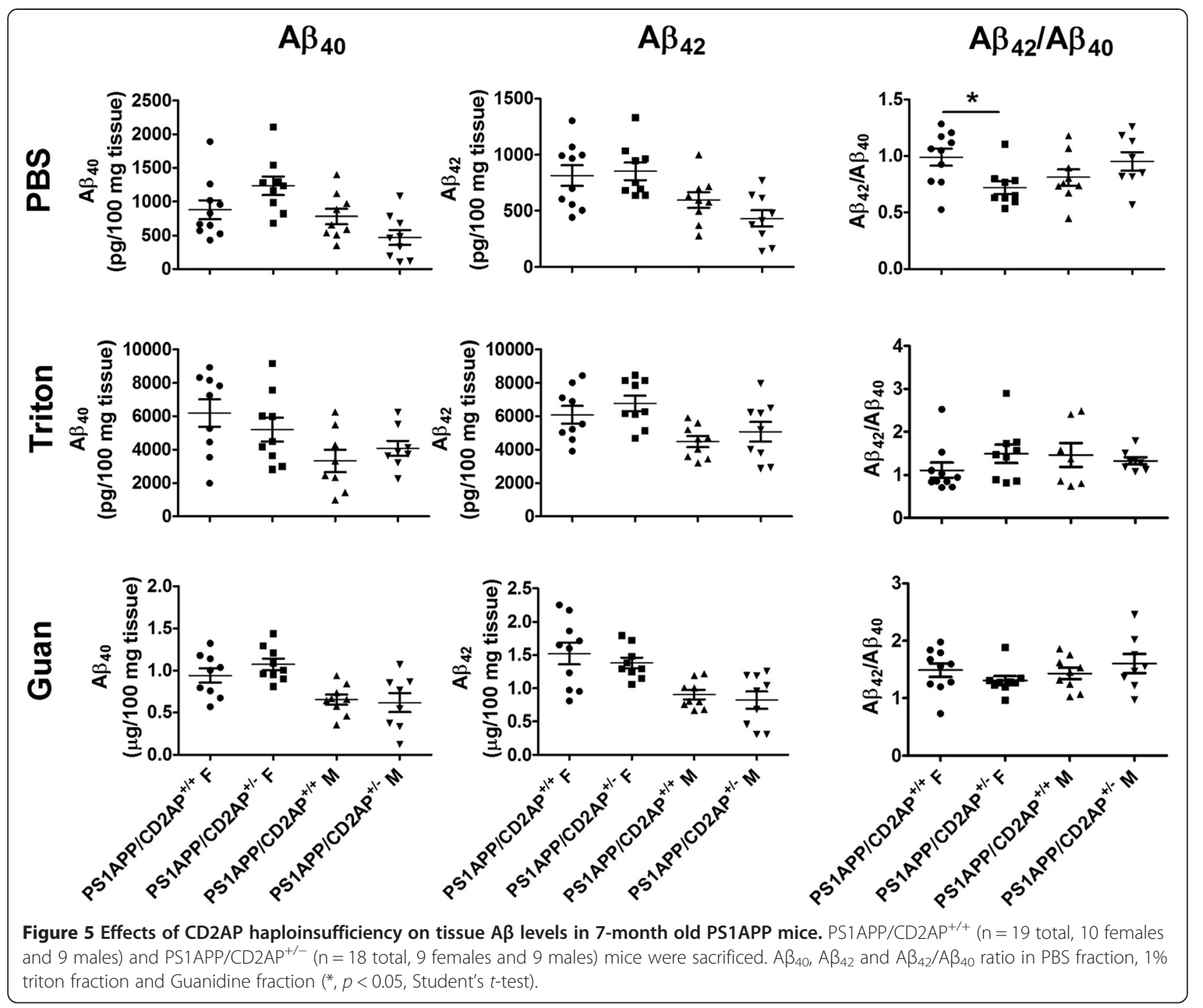

To determine whether CD2AP haploinsufficiency affects the morphology or other properties of the $A \beta$ plaques, we stained the tissue with biotinylated anti- $\mathrm{A} \beta_{1-13}$ monoclonal antibody HJ3.4B (Figure 6A) or Thioflavin S (Figure 6C) which stains fibrillar forms of $A \beta$ plaques. We did not observe any significant changes in plaque distribution, individual plaque size or plaque morphology associated with CD2AP gene status. We further quantified the $\%$ area covered with plaques in the cortex. The results demonstrated that neither $\mathrm{A} \beta$ immunostained plaques (Figure 6B) nor fibrillar plaques (Figure 6D) were different in mice with CD2AP haploinsufficiency. Taken together, although CD2AP haploinsufficiency lowered the $A \beta_{42} / A \beta_{40}$ ratio in PBS fraction of female PS1APP mice, the majority of our data demonstrate that CD2AP haploinsufficiency did not cause changes in $A \beta$ accumulation.

For certain genes that have clear effects on $A \beta$ metabolism and deposition such as apolipoprotein E or PICALM, a $50 \%$ reduction of expression has significant effects on $\mathrm{A} \beta$ pathology [26,27]. However, in our in vivo studies, lowering of CD2AP expression levels by $50 \%$ in the $\mathrm{PS} 1 \mathrm{APP} / \mathrm{CD} 2 \mathrm{AP}^{+/-}$mice did not affect $\mathrm{A} \beta$ pathology as assessed by biochemical or histological methods as compared to that in control PS1APP/CD2AP ${ }^{+/+}$mice at the age of 7 -months. It is possible that expression of $50 \%$ the level of CD2AP is sufficient to maintain adequate CD2AP function in the brain. In the future, additional work on CD2AP conditional knockout mice which live a longer life-span can be done to verify the effects of CD2AP on amyloid deposition in mice expressing lower than levels found in C2DAP haploinsufficiency in the brain.

\section{Conclusions}

In summary, we demonstrated that knocking down CD2AP in cultured N2A-APP695 cells reduces $A \beta_{40}, A \beta_{42}$ and the ratio of $A \beta_{42} / A \beta_{40}$ released into cell culture 


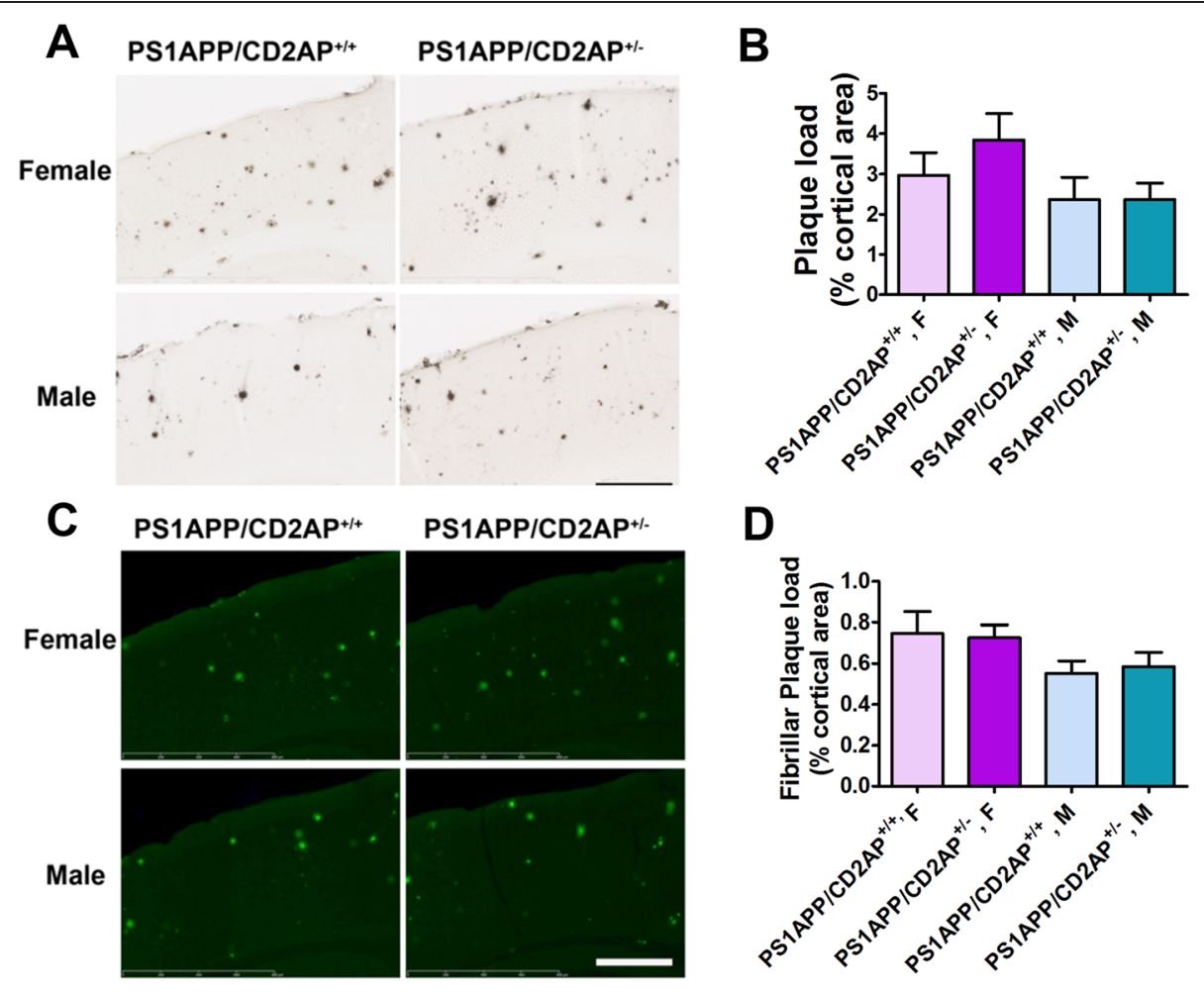

Figure 6 Effects of CD2AP haploinsufficiency on A $\beta$ plaque deposition in 7-month old PS1APP mice. PS1APP/CD2AP ${ }^{+/+}(n=19$ total, 10 females and 9 males) and PS1APP/CD2AP ${ }^{+-}(n=18$ total, 9 females and 9 males) mice were sacrificed. (A) Representative images for A $\beta$ staining in PS1APP/CD2AP ${ }^{+/+}$and PS1APP/CD2AP ${ }^{+/-}$cortex (Scale bar $=400 \mu \mathrm{m}$ ). (B) Quantification of A $\beta$ plaque load in PS1APP/CD2AP ${ }^{+/+}$and PS1APP/ $\mathrm{CD} \mathrm{AP}^{+/-}$cortex. (C) Representative images of Thioflavin S staining in PS1APP/CD2AP ${ }^{+/+}$and PS1APP/CD2AP ${ }^{+/-}$cortex $(S c a l e ~ b a r=400 \mu m)$. (D) Quantification of fibrillar plaque load in PS1APP/CD2AP ${ }^{+/+}$and PS1APP/CD2AP ${ }^{+/-}$cortex.

medium. CD2AP expression is readily detectable in the brain and so we extended out in vitro studies to an APP mouse model. In 1-month old PS1APP mice, a complete loss of CD2AP reduced the $A \beta_{42} / A \beta_{40}$ ratio in the cortical tissue but the absolute levels of $A \beta_{40}$ and $A \beta_{42}$ were unaltered. In 7-month old PS1APP mice, CD2AP haploinsufficiency did not cause significant changes in $A \beta$ pathology as analyzed by biochemical and histological assays. In the future, conditional knockout of $\mathrm{CD} 2 \mathrm{AP}$ in different brain cells can be produced to further confirm or refute the effects of CD2AP on $A \beta$ pathology. Primary neurons cultured from PS1APP/CD2AP ${ }^{-/-}$mice need to be used to confirm the in vitro effects of CD2AP on $A \beta$ production and release. Besides $A \beta$ plaques, another hallmark of $\mathrm{AD}$ is the accumulation of insoluble tau protein in structures such as intracellular neurofibrillary tangles. It was found that RNAi targeting Cindr, the fly ortholog of the human CD2AP, enhances tau toxicity in a Drosophila model in a recent study [28]. Therefore, CD2AP could also modify AD status by interacting with tau or potentially via other mechanisms. In the future, additional possible mechanisms should be explored to establish the mechanism(s) underlying the role of CD2AP in AD pathogenesis.

\section{Methods}

\section{Animals}

APPswe/PS1 $\triangle \mathrm{E} 9$ (PS1APP) mice overexpressing a chimeric mouse/human APP695 Swedish gene and human PSEN1 with an exon 9 deletion on a B6C3 background [25] were crossed with $\mathrm{CD} 2 \mathrm{AP}^{+/-}$mice on $\mathrm{B} 6$ background [14] to generate PS1APP/CD2AP ${ }^{+/-}$ and PS1APP/CD2AP ${ }^{+/+}$(control) mice. To generate $\mathrm{PS} 1 \mathrm{APP} / \mathrm{CD} 2 \mathrm{AP}^{-/-}$and PS1APP/CD2AP ${ }^{+/+}$(control) mice, the PS1APP/CD2AP ${ }^{+/-}$mice were crossed with $\mathrm{CD}_{2} \mathrm{AP}^{+/-} /$nephrin $\mathrm{Tg}$ mice. The nephrin $\mathrm{Tg}$ mice express $\mathrm{CD} 2 \mathrm{AP}$ driven by mouse nephrin promoter which directs expression specifically in podocytes [29]. On the day of harvesting, the mice were perfused with ice-cold PBS containing $0.3 \%$ heparin. For the 7-month old PS1APP/CD2AP ${ }^{+/-}$and PS1APP/ $\mathrm{CD}_{2} \mathrm{AP}^{+/+}$mice, one hemibrain was fixed in $4 \%$ paraformaldehyde for immunohistochemistry. The other hemibrain was dissected and flash-frozen on dry ice for biochemical assays. For all other animals, both sides of the brain were dissected for biochemical assays. All experimental protocols were approved by the Animal Studies Committee at Washington University. 


\section{CD2AP knockdown in cultured cells}

N2a-APP695 cells were grown in DMEM/Opti-MEM (50:50) supplemented with 5\% FBS and $200 \mu \mathrm{g} / \mathrm{ml}$ of G418. Control (firefly luciferase target sequence, fLuc; GCTTACGCTGAGTACTTCGA) and two different CD2AP-specific shRNA duplexes (CD2AP target sequences, CD2AP sh1 and sh2: GTGGAACCCTGAACAATAAG and GGAACCAATGAAGATGAACTTACA, respectively) were cloned into the pFLRu lentivirus as previously described [30]. Viral supernatants were generated in $293 \mathrm{~T}$ cells by transfection of the lentiviral plasmids with Lipofectamine 2000 (Invitrogen) and the packaging plasmids as described. Pooled supernatants, harvested at 24 and 48 hours post-transfection, were applied to N2a cells with $8 \mathrm{ug} / \mathrm{ml}$ polybrene and spun at room temperature for 2 hours at $2000 \mathrm{rpm}$. Supernatants were replaced with fresh medium immediately after centrifugation. To confirm the knock down of CD2AP, the level of CD2AP protein in RIPA cell lysates was assessed by western blot using a rabbit anti-CD2AP polyclonal antibody [1]. Actin was detected using a mouse monoclonal antibody (Sigma) which served as internal control. The cells were then cultured in a 12-well plate in serum free medium at a density of $80 \%$. After $8 \mathrm{hrs}$, the cell culture medium was collected and the cells were homogenized in RIPA buffer. The $A \beta_{40}$ and $A \beta_{42}$ in the cell culture medium and cell lysates were measured by sandwich ELISA. All the values were normalized to the protein concentration in the cell lysate to correct for the differences caused by different cell numbers in each well. To assess total APP and membrane APP, N2a-fluc, N2a-sh1 and N2a sh2 cells were cultured in a 6-well plate at a density of $90 \%$. The membrane proteins were biotinylated by incubating the cells with EZ-Link Sulfo-NHS-SS-Biotin (Thermo Scientific) on ice for $30 \mathrm{~min}$. Then the cells were homogenized in lysate buffer containing $50 \mathrm{mM}$ Tris- $\mathrm{HCl}, \mathrm{pH} 7.5,150 \mathrm{mM} \mathrm{NaCl}, 1 \%$ (v/v) Nonidet P-40, $0.5 \%(\mathrm{w} / \mathrm{v})$ deoxycholate, and $1 \times$ protease inhibitor mixture [27]. Total APP in the cell lysates was assessed using western blot with a rabbit anti-APP polyclonal antibody (Zymed). The value was normalized to actin in the same lysates. Cell lysates containing same amount of total protein were incubated with Dynabeads ${ }^{\circ} \mathrm{MyOne}^{\mathrm{m}}$ Streptavidin T1 (Invitrogen) to pull down biotinylated membrane protein. Western blot for APP was performed on the pull-down products to assess the membrane APP.

\section{Western blot for CD2AP in brain lysates}

Four-week old CD2AP ${ }^{+/+}, \mathrm{CD} 2 \mathrm{AP}^{+/-}$and $\mathrm{CD} 2 \mathrm{AP}^{-/-}$mice were perfused with ice-cold PBS containing $0.3 \%$ heparin. The cortices were dissected and homogenized in RIPA buffer. CD2AP was detected by western blot using a rabbit anti-CD2AP polyclonal antibody [1]. The western blot bands were quantified using image J (National Institutes of Health). The levels of CD2AP were normalized using tubulin values from the same sample.

\section{ELISA}

For 1-month old PS1APP/CD2AP ${ }^{-/-}$and PS1APP/ $\mathrm{CD} 2 \mathrm{AP}^{+/+}$(control) mice, brain cortices were homogenized in PBS in the presence of $1 \times$ protease inhibitor mixture (Roche). For 7-month old PS1APP/CD2AP ${ }^{+/-}$and $\mathrm{PS} 1 \mathrm{APP} / \mathrm{CD} 2 \mathrm{AP}^{+/+}$mice, brain cortices were sequentially homogenized with cold PBS, $1 \%$ Triton, and $5 \mathrm{M}$ guanidine buffer in the presence of $1 \times$ protease inhibitor mixture. The levels of $A \beta_{40}$ and $A \beta_{42}$ were measured by sandwich ELISA. For $A \beta_{40}$ or $A \beta_{42}$, anti-A $\beta_{35-40}$ HJ2 or anti-A $\beta_{37-42}$ HJ7.4 were used as capture antibodies, and anti-A $\beta_{13-28}$ HJ5.1-biotin [6] was used as detecting antibody.

\section{Immunohistochemistry}

Serial coronal sections at 50- $\mu \mathrm{m}$ thickness were collected from the rostral to the caudal end of each brain hemisphere using a freezing sliding microtome (Leica). $A \beta$ plaques were immunostained using biotinylated anti- $\mathrm{A} \beta_{1-13}$ monoclonal antibody HJ3.4B [31].

\section{Thioflavine S staining}

For fibrillar plaques, brain sections were stained with 0.025\% Thioflavin S (Sigma) in 50\% ethanol for $10 \mathrm{~min}$. Then the sections were washed with $50 \%$ ethanol twice followed by PBS [32].

\section{Imaging}

Immunostained brain sections were scanned using a Nanozoomer slide scanner (Hamamatsu Photonics). Quantitative analysis of immunopositive staining was performed as previously described [33]. Briefly, images of immunostained sections were exported with NDP viewer (Hamamatsu Photonics), converted to 8-bit grayscale using ACDSee Pro 2 software (ACD Systems) and threshold was set to highlight positive staining and analyzed using ImageJ (National Institutes of Health). 3 sections per mouse (Bregma, $-1.4 \mathrm{~mm}$ caudal to Bregma, $-2.0 \mathrm{~mm}$ caudal to Bregma) were quantified (the cortex immediately dorsal to the hippocampus) and the average was used to represent each mouse.

\section{Statistics}

Two-tailed Student's $t$-test was used to determine if there were significant differences between two groups unless otherwise specified. One-way ANOVA was used to compare differences among 3 or more groups followed by Tukey post-test unless otherwise specified. Data in all the figures are expressed as mean \pm S.E.M unless otherwise specified. 


\section{Abbreviations}

CD2AP: CD2-Associated protein; Aß: Amyloid- $\beta$; AD: Alzheimer's disease; SH3KBP1: SH3-domain kinase binding protein 1; PICALM: Phosphatidylinositol clathrin assembly lymphoid-myeloid leukemia.

\section{Competing interests}

$\mathrm{DMH}$ is a co-founder and is on the scientific advisory board of $\mathrm{C} 2 \mathrm{~N}$ Diagnostics, LLC. DMH consults for AstraZeneca, Genentech, Eli Lilly, and Neurophage. Washington University receives grants to the lab of $\mathrm{DMH}$ from C2N Diagnostics, Eli Lilly, and Janssen.

\section{Authors' contributions}

FL, SS, JML, ASS and DMH participated in the design of the study. FL, HJ, SS, QX, KBL, KY and TEM carried out the experiments, collected and analyzed the data. FL, SS, QX, ASS and DMH were involved in drafting the manuscript. All authors have given final approval of the version to be published and agree to be accountable for all aspects of the work in ensuring that questions related to the accuracy or integrity of any part of the work are appropriately investigated and resolved.

\section{Acknowledgements}

This work was supported by the Cure Alzheimer's Fund (DMH), the JPB Foundation (DMH), NIH/NINDS R21 NS082529 (JML), HHMI (ASS), NIH Al57966 (ASS) and NIH DK96688 (ASS).

\section{Author details \\ 'Department of Neurology, Hope Center for Neurological Disorders, Charles F. and Joanne Knight Alzheimer's Disease Research Center, Washington University School of Medicine, St. Louis, MO, USA. ${ }^{2}$ Department of Pathology and Immunology, Washington University School of Medicine, St. Louis, MO, USA. ${ }^{3}$ Department of Neurology, Hope Center for Neurological Disorders, Washington University School of Medicine, St. Louis, MO, USA. ${ }^{4}$ Department of Neurology, Washington University School of Medicine, St. Louis, MO, USA. ${ }^{5}$ Department of Neuropathology, Graduate School of Medicine, The University of Tokyo, Tokyo, Japan.}

\section{Received: 31 January 2015 Accepted: 26 February 2015 Published online: 19 March 2015}

\section{References}

1. Dustin ML, Olszowy MW, Holdorf AD, Li J, Bromley S, Desai N, et al. A novel adaptor protein orchestrates receptor patterning and cytoskeletal polarity in T-cell contacts. Cell. 1998;94:667-77.

2. Shaw AS. T-cell activation and immunologic synapse. Immunol Res. 2005;32:247-52.

3. Holtzman DM, Morris JC, Goate AM. Alzheimer's disease: the challenge of the second century. Sci Transl Med. 2011;3:77sr-71.

4. Hardy J, Selkoe DJ. The amyloid hypothesis of Alzheimer's disease: progress and problems on the road to therapeutics. Science. 2002;297:353-6.

5. Lemere CA, Masliah E. Can Alzheimer disease be prevented by amyloid-beta immunotherapy? Nat Rev Neurol. 2010;6:108-19.

6. Bero AW, Yan P, Roh JH, Cirrito JR, Stewart FR, Raichle ME, et al. Neurona activity regulates the regional vulnerability to amyloid-beta deposition. Nat Neurosci. 2011:14:750-6.

7. Cirrito JR, Kang JE, Lee J, Stewart FR, Verges DK, Silverio LM, et al. Endocytosis is required for synaptic activity-dependent release of amyloid-beta in vivo. Neuron. 2008;58:42-51.

8. Hollingworth P, Harold D, Sims R, Gerrish A, Lambert JC, Carrasquillo MM, et al. Common variants at ABCA7, MS4A6A/MS4A4E, EPHA1, CD33 and CD2AP are associated with Alzheimer's disease. Nat Genet. 2011:43:429-35.

9. Naj AC, Jun G, Beecham GW, Wang LS, Vardarajan BN, Buros J, et al. Common variants at MS4A4/MS4A6E, CD2AP, CD33 and EPHA1 are associated with late-onset Alzheimer's disease. Nat Genet. 2011:43:436-41.

10. Lambert JC, Ibrahim-Verbaas CA, Harold D, Naj AC, Sims R, Bellenguez C, et al. Meta-analysis of 74,046 individuals identifies 11 new susceptibility loci for Alzheimer's disease. Nat Genet. 2013;45:1452-8.
11. Gaidos G, Soni S, Oswald DJ, Toselli PA, Kirsch KH. Structure and function analysis of the CMS/CIN85 protein family identifies actin-bundling properties and heterotypic-complex formation. J Cell Sci. 2007;120:2366-77.

12. Treusch S, Hamamichi S, Goodman JL, Matlack KE, Chung CY, Baru V, et al. Functional links between Abeta toxicity, endocytic trafficking, and Alzheimer's disease risk factors in yeast. Science. 2011:334:1241-5.

13. Shulman JM, Chen K, Keenan BT, Chibnik LB, Fleisher A, Thiyyagura P, et al Genetic susceptibility for Alzheimer disease neuritic plaque pathology. JAMA Neurol. 2013;70:1150-7.

14. Shih NY, Li J, Karpitskii V, Nguyen A, Dustin ML, Kanagawa O, et al. Congenital nephrotic syndrome in mice lacking CD2-associated protein. Science. 1999;286:312-5.

15. Haass C, Kaether C, Thinakaran G, Sisodia S. Trafficking and proteolytic processing of APP. Cold Spring Harb Perspect Med. 2012;2:a006270.

16. Koo EH, Squazzo SL. Evidence that production and release of amyloid beta-protein involves the endocytic pathway. J Biol Chem. 1994;269:17386-9.

17. Kim JM, Wu H, Green G, Winkler CA, Kopp JB, Miner JH, et al. CD2-associated protein haploinsufficiency is linked to glomerular disease susceptibility. Science. 2003:300:1298-300.

18. Deane R, Wu Z, Sagare A, Davis J, Du Yan S, Hamm K, et al. LRP/amyloid beta-peptide interaction mediates differential brain efflux of Abeta isoforms. Neuron. 2004;43:333-44.

19. Levy-Lahad E, Wasco W, Poorkaj P, Romano DM, Oshima J, Pettingell WH, et al. Candidate gene for the chromosome 1 familial Alzheimer's disease locus. Science. 1995;269:973-7.

20. Sherrington R, Rogaev El, Liang Y, Rogaeva EA, Levesque G, Ikeda M, et al. Cloning of a gene bearing missense mutations in early-onset familial Alzheimer's disease. Nature. 1995:375:754-60.

21. Dimitrov M, Alattia JR, Lemmin T, Lehal R, Fligier A, Houacine J, et al. Alzheimer's disease mutations in APP but not gamma-secretase modulators affect epsilon-cleavage-dependent AICD production. Nat Commun. 2013:4:2246.

22. Esselens C, Sannerud R, Gallardo R, Baert V, Kaden D, Serneels L, et al. Peptides based on the presenilin-APP binding domain inhibit APP processing and Abeta production through interfering with the APP transmembrane domain. FASEB J. 2012:26:3765-78.

23. Kanatsu K, Morohashi Y, Suzuki M, Kuroda H, Watanabe T, Tomita T, et al. Decreased CALM expression reduces Abeta42 to total Abeta ratio through clathrin-mediated endocytosis of gamma-secretase. Nat Commun. 2014:5:3386.

24. Singh J, Mlodzik M. Hibris, a Drosophila nephrin homolog, is required for presenilin-mediated Notch and APP-like cleavages. Dev Cell. 2012;23:82-96

25. Jankowsky JL, Fadale DJ, Anderson J, Xu GM, Gonzales V, Jenkins NA, et al. Mutant presenilins specifically elevate the levels of the 42 residue beta-amyloid peptide in vivo: evidence for augmentation of a 42 -specific gamma secretase. Hum Mol Genet. 2004;13:159-70.

26. Kim J, Jiang H, Park S, Eltorai AE, Stewart FR, Yoon $H$, et al. Haploinsufficiency of human APOE reduces amyloid deposition in a mouse model of amyloid-beta amyloidosis. J Neurosci. 2011;31:18007-12.

27. Xiao Q, Gil SC, Yan P, Wang Y, Han S, Gonzales E, et al. Role of phosphatidylinositol clathrin assembly lymphoid-myeloid leukemia (PICALM) in intracellular amyloid precursor protein (APP) processing and amyloid plaque pathogenesis. J Biol Chem. 2012;287:21279-89.

28. Shulman JM, Imboywa S, Giagtzoglou N, Powers MP, Hu Y, Devenport D, et al. Functional screening in Drosophila identifies Alzheimer's disease susceptibility genes and implicates Tau-mediated mechanisms. Hum Mol Genet. 2014;23:870-7.

29. Grunkemeyer JA, Kwoh C, Huber TB, Shaw AS. CD2-associated protein (CD2AP) expression in podocytes rescues lethality of CD2AP deficiency. J Biol Chem. 2005;280:29677-81.

30. Feng $Y$, Nie L, Thakur MD, Su Q, Chi Z, Zhao Y, et al. A multifunctional lentiviral-based gene knockdown with concurrent rescue that controls for off-target effects of RNAi. Genomics Proteomics Bioinformatics. 2010;8:238-45.

31. Liao F, Zhang TJ, Mahan TE, Jiang H, Holtzman DM. Effects of growth hormone-releasing hormone on sleep and brain interstitial fluid amyloid-beta in an APP transgenic mouse model. Brain Behav Immun. 2014. doi: 10.1016/j.bbi.2014.09.005. 
32. Liao F, Hori $Y$, Hudry E, Bauer AQ, Jiang H, Mahan TE, et al. Anti-ApoE antibody given after plaque onset decreases Abeta accumulation and improves brain function in a mouse model of Abeta amyloidosis. J Neurosci. 2014;34:7281-92.

33. Bero AW, Bauer AQ, Stewart FR, White BR, Cirrito JR, Raichle ME, et al. Bidirectional relationship between functional connectivity and amyloid-beta deposition in mouse brain. J Neurosci. 2012;32:4334-40.

Submit your next manuscript to BioMed Central and take full advantage of:

- Convenient online submission

- Thorough peer review

- No space constraints or color figure charges

- Immediate publication on acceptance

- Inclusion in PubMed, CAS, Scopus and Google Scholar

- Research which is freely available for redistribution 